\title{
Distintos sujetos bajo un mismo predicado: reflexión historiográfica sobre la historia empresarial en el Caribe colombiano
}

\author{
Ana Milena Rhenals Doria \\ Francisco J. Flórez Bolivar ${ }^{\left({ }^{*}\right)}$
}

Recibido: julio de 2011

Aprobado: octubre de 2011

\section{Resumen}

En este artículo se presenta una revisión bibliográfica de los estudios empresariales sobre el Caribe colombiano en los últimos veinte años. Intentamos determinar los ritmos historiográficos que han caracterizado a este tipo de interpretaciones, que inicialmente fueron útiles al ayudar explorar diversas facetas de la vida económica de la región, pero que parecen mostrar cierto agotamiento. Nos interesa sugerir que para salir del estancamiento en que se encuentran estos estudios, aparte de integrar las dinámicas históricas que han caracterizado a esta región, deben articular sus hallazgos con los realizados en el ámbito de la historia socio-cultural, y con ello establecer los nexos causales existentes entre las bases de poder económico descrito por los estudios empresariales y las configuraciones socio-políticas que resultaron de la interacción con el resto de conglomerados sociales.

\section{Palabras Claves}

Historia empresarial, inmigrantes, historiografia, Caribe colombiano.

\begin{abstract}
This article presents a literature review of studies on the Colombian Caribbean business in the last twenty years. Historiographical trying to determine the rates that have characterized this type of interpretation, initially were useful in helping to explore various facets of economic life in the region, but show some depletion Parenco. We are interested to suggest that to break the stalemate in these studies, apart from integrating the historical dynamics that have characterized this region, must articulate its findings with those in the field of socio-cultural history, and thereby establish the causal links between the economic power bases described by business studies and socio-political configurations that resulted from the interaction with other social clusters.
\end{abstract}

Key words:

Business history, immigrant history, the Colombian Caribbean.

${ }^{(*)}$ Ana Milena Rhenals. Historiadora de la Universidad de Cartagena, y candidata a Doctora en Historia de América Latina de la Universidad Pablo de Olavide, Sevilla-España. Su tesis de maestría sobre las actividades mercantiles y los vínculos sociales de los inmigrantes sirio-libaneses en el circuito comercial de la provincia del Sinú y Cartagena recibió calificación Sobresaliente Cum laude, y actualmente se desempeña como profesora catedrática de la Universidad Tecnológica de Bolívar. Es miembro del grupo de investigación Sociedad, Cultura y Política en el Caribe colombiano. directora de la revista Trenzando. mirhedo@yahoo.es

Francisco Flórez Bolívar. Historiador de la Universidad de Cartagena. Ha sido profesor catedrático del Programa de Historia de esta institución, joven investigador de Colciencias. Becario Fullbrigth estudios doctorales en los Estados Unidos. Ha publicado artículos en las revistas Historia Caribe (Universidad del Atlántico), Historia y espacio (Universidad del Valle), Sociedad y Economía (Universidad del Valle) y Trenzando. Es miembro del grupo de investigación Sociedad, Cultura y Política en el Caribe colombiano. Editor de la revista Trenzando.pachohistory18@hotmail.com 


\section{Presentación}

$\mathrm{E}$ n los últimos veinte años el panorama historiográfico del Caribe colombiano se ha visto fortalecido y renovado por un significativo número de estudios que han facilitado la comprensión de las decisivas dinámicas históricas que intervinieron en la configuración de este espacio como región. Desde distintas perspectivas y métodos, se ha ido pintando un cuadro más complejo sobre los procesos económicos, sociales, políticos y culturales que tipificaron las realidades de los distintos espacios y grupos sociales de la región Caribe a lo largo del periodo colonial, así como sobre los hechos que han caracterizado el desarrollo de esta región en el transcurso de la compleja vida republicana ${ }^{1}$.

Dentro de este cuadro cabe mencionar la importancia que han ido cobrando temas como la vida cotidiana, las relaciones de género, la creación de espacios de sociabilidad, los conflictos socio-raciales, las representaciones políticas y sociales, la irrupción de los discursos de ciudadanía, los proyectos educativos y su relación con la expansión de los valores republicanos, el papel de los grupos artesanales y en general de los sectores populares en la definición de identidades políticas y sociales, las relaciones de poder en los espacios de frontera, la dinámica comercial de los centros portuarios de la región Caribe, y el peso que tuvieron los empresarios y comerciantes nacionales y extranjeros en el desarrollo económico de la región ${ }^{2}$.

\footnotetext{
${ }^{1}$ Hermes Tovar, "la historiografía sobre Cartagena de Indias en el siglo XVIII" y Sergio Paolo Solano, "Un siglo de ausencia: la historiografía de Cartagena en el siglo XX", en Adolfo Meisel y Haroldo Calvo (eds.), Cartagena de Indias y su historia, Bogotá, Banco de la Republica-Universidad Jorge Tadeo Lozano, 1998, pp. 21-79 y 215-232 respectivamente. José Polo, "La historia como saber y disciplina en el Caribe colombiano, 1995-2005: Desafíos y perspectivas”, en Aaron Espinosa (ed.), Respirando el Caribe. Memorias del II Encuentro de Investigadores sobre el Caribe colombiano, Bogotá, ColcienciasObservatorio del Caribe Colombiano, 2006, pp. 27-54.

2 José Polo, Etnicidad, conflicto social y cultura fronteriza en la Guajira, 1700-1850, Bogotá, Universidad de los Andes-Ministerio de Cultura-Observatorio del Caribe Colombiano, 2005; Sergio Paolo Solano, Puertos, sociedad y conflicto en el Caribe colombiano 1850-1930, Bogotá, Ministerio de CulturaObservatorio del Caribe Colombiano-Universidad de Cartagena, 2003; Alfonso Múnera, El Fracaso de la nación. Región, raza y clase en el Caribe colombiano, 1717-1810, Bogotá, Banco de la República-El Áncora eds., 1998 y Fronteras imaginadas. La construcción de las razas y la geografía en el siglo XIX colombiano, Bogotá, Planeta, 2005; Raúl Román, "Memoria y contramemoria: el uso público de la historia", en Desorden en la plaza, Cartagena, Fondo Mixto de Cultura, 2003; Roicer Flórez Bolívar, "Ciudadanos y vecinos: un acercamiento al proceso de construcción del ciudadano en Cartagena durante la primera mitad del siglo XIX” y Francisco Flórez Bolívar “¿República democrática o 'república de papel?’: los artesanos frente al ideario liberal en Cartagena, 1848-1878", en Historia Caribe № 12, Barranquilla, Universidad del Atlántico, 2006, pp. 111-144; Sergio Paolo Solano y Roicer Flórez Bolívar, "Resguardos indígenas, ganadería y conflictos sociales en el Bolívar Grande, 1850-1875”, en Historia Critica $\mathrm{N}^{\circ} 34$, Bogotá, Universidad de los Andes, 2007, pp. 92-117; Sergio Paolo Solano y Roicer Flórez Bolívar, "Del texto al contexto. Cosme y la sociedad urbana del Caribe colombiano a comienzos del siglo XX", en Cuadernos de Literatura del Caribe e Hispanoamérica $\mathrm{N}^{\circ} 7$, Barranquilla, Universidad del AtlánticoUniversidad de Cartagena, 2008, pp. 173-217; Sergio Paolo Solano, Roicer Flórez Bolívar y William Malkún, "Ordenamiento territorial y conflictos jurisdiccionales en el Bolívar Grande, 1800-1886", en Historia Caribe $\mathrm{N}^{\mathrm{0}}$ 13, Barranquilla, Universidad del Atlántico, 2008, pp. 65-119; Sergio Paolo Solano, "La novela Yngermina de Juan José Nieto y el mundo racial del Bolívar Grande (Colombia) en el siglo XIX”, en Revista de Estudios Sociales No 31, Bogotá, Universidad de los Andes, 2008, pp. 34-47; Adolfo
}

El Taller de la Historia, vol. III, $N^{\circ}$ 3, 2011, págs. 139-160. Issn: 1657-3633

Programa de Historia, Facultad de Ciencias Humanas, Universidad de Cartagena de Indias, Colombia 
Pese a que se pueden establecer e identificar unas variaciones historiográficas sintetizadas en el interés por la ya recuperada historia política, y un marcado desplazamiento hacia las perspectivas sociales y culturales, no cabe duda que la realidad histórica sobre la cual más "certezas" se han construido y consolidado hasta el momento es la perteneciente al ámbito económico, hasta el punto de haber generado diversas líneas de investigación, donde la historia empresarial ocupa un lugar privilegiado al ser una de las más estudiada en la reciente y renovada historiografía de la Costa Caribe. El propósito de la siguiente reflexión es analizar las perspectivas y ritmos historiográficos que han caracterizado los estudios empresariales en esta región de Colombia en los últimos veinte años. Aunque nos detendremos en algunos de los textos más representativos que sobre el tema se han producido, nos mueve la pretensión de ir más allá de la valoración de los trabajos analizados: intentaremos, sobre todo, ofrecer una interpretación que muestre los retos y desafíos que las investigaciones sobre esta temática parecen estar exigiendo cada vez más.

\section{Especificidades contextuales de la región Caribe colombiana}

Desde finales de los años setenta del siglo pasado diversos estudios comenzaron a cuestionarse por el papel de las elites empresariales en el desarrollo de las regiones colombianas. Inicialmente centrados en la singularidad y espectacularidad del proceso de expansión de la frontera agrícola del caso antioqueño, los estudios empresariales fueron ampliando su foco de atención para reconstruir el accionar de empresas y empresarios en espacios como Santander, el Valle del Cauca, Cundinamarca y la zona cafetera, hasta el punto que a mediados de los años 90s se dio un explosivo desarrollo de este tipo de análisis que ya cuentan tanto con textos ampliamente inspirados en lograr una comprensión nacional de los procesos asociados a los mencionados empresarios, como con balances historiográficos que han ponderado las fortalezas y falencias de este tipo de interpretaciones $^{3}$. La historiografía del Caribe colombiano no ha escapado a este auge de

Meisel (ed.), Historia económica y social del Caribe colombiano, Barranquilla, eds. Uninorte-Ecoe, 1994; Jorge Conde Calderón, Luís Alarcón Meneses y Adriana Santos, Educación y cultura en el Estado Soberano del Magdalena, 1857-1886, Barranquilla, Universidad del Atlántico, 2002; Eduardo Posada, El Caribe colombiano, una historia regional (1870-1950), Bogotá, Banco de la República-El Áncora eds., 1995; Aline Helg, Liberty and equality in Caribbean Colombia, 1770-1835, Chapell Hill, University of North Carolina Press, 2004; Steinar Saether, Identidades e independencia en Santa Marta y Riohacha, 1750-1850, Bogotá, Icanh, 2005, Marixa Lasso, Myhts of harmony: race and republicanism during the age of revolution 1795-1831, Pittsburgh, Pittsburgh University Press, 2007; Gloria Bonilla, "las mujeres en la prensa de Cartagena, prácticas y discursos", en Unicarta $\mathrm{N}^{\mathrm{o}} 100$, Cartagena, Universidad de Cartagena, 2003; María Teresa Ripoll, Empresarios centenaristas en Cartagena. Cuatro casos de estudio, Cartagena, Universidad Tecnológica de Bolívar-Universidad de los Andes, 2008; La elite en Cartagena y su tránsito a la república. Revolución política sin renovación social, Bogotá, Universidad de los Andes, 2006.

${ }^{3}$ Carlos Dávila, Los comienzos de la historia empresarial en Colombia, 1975-1995, Ponencia presentada en las XV jornadas en Historia Económica Argentina, Instituto de Investigaciones Históricas y Sociales, Universidad Nacional del centro de la Provincia de Buenos Aires, 1996; Carlos Dávila (comp.), Empresas y empresarios en la historia de Colombia. Siglos XIX y XX, 2 vols., Bogotá, Norma-Cepal-Uniandes, 2003; Luís F. Molina, Empresarios colombianos del siglo XIX, Bogotá, Banco de la República-El Áncora eds., 1998; Adolfo Meisel, Los estudios sobre historia económica de Colombia a partir de 1990: principales temáticas y aportes, Cuadernos de Historia Económica y Empresarial, Cartagena, Banco de la

El Taller de la Historia, vol. III, $N^{\circ}$ 3, 2011, págs. 139-160. Issn: 1657-3633

Programa de Historia, Facultad de Ciencias Humanas, Universidad de Cartagena de Indias, Colombia 
estudios empresariales, y desde los años 80s diversas interpretaciones han intentado determinar el peso que estos actores sociales y sus respectivas iniciativas empresariales tuvieron en la definición de los procesos que explican el desarrollo económico de esta importante región.

Y ciertamente esta zona del país - como quizás ninguna otra- cuenta con un conjunto de dinámicas históricas que la convierte en un escenario propicio para realizar esta clase de análisis. Su vocación portuaria y comercial hizo de sus tres principales centros urbanos (Barranquilla, Cartagena, Santa Marta) los puertos más dinámicos e importantes dentro del contexto colombiano durante un lapso de tiempo considerable. Cartagena durante gran parte del periodo colonial y hasta las primeras décadas del siglo XIX fue el principal puerto colombiano por donde circularon esclavos, oro, frutos, mercancías y todo con cuanto traficara el ser humano. Cartagena palpó los rigores de las confrontaciones bélicas en la guerra de Independencia y perdió su primacía dentro de la jerarquía portuaria nacional, siendo remplazada en los años 40 de esa centuria por Santa Marta, y luego por el vecino puerto de Barranquilla en la segunda mitad del siglo XIX ${ }^{4}$.

De esta vocación portuaria derivan varios aspectos fundamentales de la vida política, social y cultural de la región que -como veremos- al tiempo que hicieron de este territorio un campo propicio para el desarrollo de estudios empresariales, se han convertido muchas veces en variables que han llevado a omisiones, sobrevaloraciones e insuficiencias en los marcos interpretativos de quienes han realizado este tipo de análisis. Quizás uno de los aspectos más importantes, ampliamente anotado por la historiografía, es la notable presencia y consolidación de un grupo de comerciantes y empresarios que no solo tuvo incidencia en el ámbito de la vida económica sino también en las esferas del control político y socio-cultural de sus respectivas sociedades. Empresarios, oportunistas y especularadores, aprovechando esta dinámica vida comercial y portuaria, se fueron ubicando en la región Caribe colombiana, razón por la cual en este territorio se ubicó un numero considerable de inmigrantes compuestos por españoles, franceses, alemanes, italianos y, sobre todo, sirios, palestinos y libaneses que terminaron integrándose a través de diversos mecanismos a las distintas esferas de las ciudades, provincias y pueblos de la región 5 .

República (CEER), marzo, 2005. Una visión critica sobre la historia empresarial en Colombia la ofrece Gilberto Betancourt, "De la historia empresarial la historia organizacional", en Innovar vol. 13, $\mathrm{N}^{\circ} 22$, Bogotá, Universidad Nacional de Colombia, 2003, pp. 199-210.

${ }^{4}$ Theodore Nichols, Tres puertos de Colombia. Estudio sobre el desarrollo de Cartagena, Santa Marta y Barranquilla, Bogotá, Banco Popular, 1973.

${ }^{5}$ Sobre los empresarios en Cartagena véase el texto inicial de Jorge Restrepo y Manuel Rodríguez, "La actividad comercial en Cartagena y el grupo de comerciantes de Cartagena a finales del siglo XIX", en Estudios Sociales No 1, Medellín, Faes, 1986, pp. 46-101. Estos autores ofrecen una visión inicial sobre el papel de los inmigrantes en la vida social, económica y política de Barranquilla en su articulo "Los empresarios extranjeros de Barranquilla, 1820-1900”, en Gustavo Bell (comp.), El Caribe colombiano, Barranquilla, Uninorte, 1988, pp. 139-193. 
De gran significado dentro de las complejas realidades económicas esta región es el entendimiento de los procesos ligados al consuetudinario contrabando que ha caracterizado su historia. Desde el periodo colonial el comercio ilícito se convirtió en un aspecto central de la vida económica y social de la Costa Caribe. La ineficiencia de las autoridades coloniales por controlar espacios considerados como de frontera se hizo evidente en el intenso tráfico ilícito que caracterizó a la Guajira, Santa Marta, Cartagena, y a las ricas poblaciones del Sinú. Esta práctica ilegal definió en buena parte los ritmos de vida de los habitantes de esta formación social, no porque sea una condición inherente o cultural sino porque simple y llanamente las evidencias históricas muestran que las autoridades civiles, eclesiásticas, políticas y militares, al lado de grandes comerciantes, buhoneros y vendedores ambulantes, participaban del tráfico y comercio ilegal de mercancías que se prolongó durante buena parte de la vida republicana ${ }^{6}$.

La última variable que nos interesa resaltar y que complementa este cuadro económico se expresa en la estrecha relación que estos puertos establecieron con sus respectivos hinterland, caracterizados por ser ricos en productos agrícolas y propicios para el desarrollo de la ganadería. Empresarios nacionales y extranjeros explotaron las posibilidades que las sabanas de Bolívar, el promisorio Valle del Sinú y las zonas bananeras del Magdalena ofrecían para el desarrollo de estas actividades económicas, y con ello encontraron el escenario para sustentar sus proyectos empresariales cuando los siempre cambiantes ciclos económicos -que han caracterizado la balanza comercial colombiana y por ende el ritmo de los puertos- suponían fuertes crisis económicas, como la que atravesó Cartagena durante buena parte del siglo XIX, y que logró superar en parte apoyándose en la diversidad de productos que para ese entonces la vibrante provincia del Sinú le ofreció a su elite económica ${ }^{7}$.

El tránsito del siglo XIX al XX, entonces, con una Cartagena recuperada, Santa Marta posicionada, $\mathrm{y}$, ante todo, Barranquilla como principal puerto de Colombia, ubicaba a esta región en una posición excepcional: cerca del $80 \%$ del comercio exterior del país circulaban por los puertos del Caribe colombiano, sirviendo como puntos de conexión entre los mercados externos y las importantes zonas de producción y de consumo del mundo andino, con un hinterland rico en productos agrícolas y ganaderos, que se beneficiaba de la presencia de diversos puertos ribereños que también servían como centros de acopio y

\footnotetext{
${ }^{6}$ El estudio más detallado y documentado es el de Muriel Laurent, Contrabando en Colombia en el siglo XIX, Bogotá, Universidad de los Andes, 2008. Otras referencias al tema pueden verse en Alfonso Múnera, "Ilegalidad y frontera 1770-1800", en A. Meisel, Historia económica y social del Caribe colombiano, pp. 109-154. José Polo, Etnicidad, poder y negociación en la frontera Guajira, 1750-1820, Informe final de investigación presentado al Instituto Colombiano de Antropología e Historia, Bogotá, 2004, y Etnicidad, conflicto social y cultura fronteriza en la Guajira, 1700-1850, y S. P. Solano, Puertos, sociedad y conflicto en el Caribe colombiano, 1850-1930, pp. 3-15.

${ }^{7}$ Una visión reciente y detallada sobre la relación entre Cartagena y la provincia del Sinú se puede ver en Ana Milena Rhenals, Inmigrantes sirio-libaneses en el Caribe colombiano: El caso de Cartagena y la provincia del Sinú (Lorica y Cereté) 1880-1930, Sevilla-España, Universidad Pablo de Olavide, 2007 (Tesis de maestría).
} 
redistribución ${ }^{8}$. Sin embargo, nuevas condiciones económicas, asociadas a la apertura del Canal de Panamá que facilitó el acceso a los mercados del exterior por el puerto de Buenaventura en la Costa Pacífica, desplazaron a los puertos del Caribe colombiano, y en especial a Barranquilla, como principal punto de salida de las exportaciones, y con ello se hizo evidente el progresivo proceso de rezago y estancamiento de la región al alejarse cada vez más del ritmo de crecimiento que ciudades como Bogotá, Medellín y, luego, Cali siguieron experimentando ${ }^{9}$.

El inusitado interés por estudiar el papel de los empresarios en la vida económica de las regiones, asociadas a las especificidades y ricas dinámicas históricas del Caribe colombiano, y la preocupación por encontrar las claves para entender el desarrollo y el por qué del mencionado rezago económico, fue el contexto que abrió paso para que economistas, historiadores y aficionados al arte de hacer historia iniciaran la ya consolidada línea de historia empresarial en esta región del país, que no ha estado exenta de falencias y vacíos de orden historiográficos e históricos.

\section{La visión esquemática de los estudios sobre los empresarios nacionales}

Uno de los primeros textos interesados en analizar el papel de los empresarios nacionales en la Costa Caribe colombiana fue el de Jorge Restrepo y Manuel Rodríguez publicado a finales de los años 80s del siglo pasado. Restrepo y Rodríguez, ante todo, estudiaron la actividad comercial de un significativo grupo de comerciantes en Cartagena a finales del siglo XIX. Es de destacar la perspectiva metodológica utilizada por los autores al mostrar a los empresarios inmersos en las diferentes dinámicas inherentes a la sociedad donde se encontraban ubicados, es decir, no solo se concentraron en la vida económica y comercial, sino que exploraron los nexos de los empresarios con los procesos sociales y políticos de Cartagena. Indagando por la participación de estos sectores en la definición de la configuración de los espacios de poder político y su inserción y articulación en los círculos sociales de la Cartagena de finales de siglo XIX, así como fue notorio su interés en construir una serie de tipologías sobre este grupo social que distaban mucho de ser homogéneo $^{10}$. Siguiendo la orientación metodológica de estos dos analistas, los historiadores Sergio Paolo Solano y Jorge Conde profundizaron y ampliaron las perspectivas de interpretación sobre el mundo empresarial en la Costa Caribe colombiana. Tomando como objeto de estudio la elite empresarial barranquillera, Solano y Conde destacaron la participación de este grupo como parte esencial del impulso económico de la

\footnotetext{
${ }^{8}$ Eduardo Posada, "Progreso y estancamiento 1850-1950", en A. Meisel, Historia económica y social del Caribe colombiano, p. 242

${ }^{9}$ Un estudio clave en esta discusión es el de Adolfo Meisel, "Por qué se disipó el dinamismo industrial de Barranquilla”, en Lecturas de Economía № 23, Medellín, Universidad de Antioquia, 1987, pp. 57-84. Del mismo autor "Rezago relativo y creciente integración, 1950-1994", en A. Meisel, Historia económica y social del Caribe colombiano, pp. 287-328.

10 J. Restrepo y M. Rodríguez, "La actividad comercial en Cartagena y el grupo de comerciantes de Cartagena a finales del siglo XIX”, pp. 46-101
} 
ciudad a nivel industrial durante los siglos XIX y XX, haciendo énfasis en el tipo de actividades económicas de orden legal e ilegal que les permitieron capitalizarse y lograr un apogeo económico que se vio representado en inversiones en el sector empresarial e industrial de la ciudad, dándose así un activo movimiento comercial y laboral ${ }^{11}$. La intención de los autores más que describir y realizar un muestreo de los empresarios barranquilleros que intervinieron en dicho proceso, es lograr analizar e interpretar las formas de conformación y consolidación de una elite empresarial en estrecha relación con el contexto geográfico, político y social, y las prácticas comerciales ilegales, como el contrabando, características del Caribe colombiano.

En los trabajos de Solano y Conde, Restrepo y Rodríguez, subyacía una agenda de investigación que iba desde una marcada preocupación por contextualizar el accionar de los mencionados empresarios, un reconocimiento explícito de las dinámicas internas y su relación con los actores sociales, pasando por una notoria preocupación por establecer semejanzas, diferencias y tendencias explicativas a partir del uso de una perspectiva comparativa, hasta llegar al convencimiento de que este tipo de análisis necesariamente debía reconocer y tener como sustrato la compleja relación entre estructura e individuo. En otras palabras, se trataba de poner en su justa proporción la influencia que tuvieron las empresas y empresarios en el desarrollo económico de sus respectivas sociedades, sin caer en una exaltación per-se de los individuos o en interpretaciones esquemáticas o motivadas por el mero sentido común que aunque útil para plantear interrogantes o cuestionar las fuentes no es suficiente para sustentar las hipótesis. La propuesta de los autores mencionados, sobre todo la de Solano y Conde, encerraba un claro ejercicio de pensar históricamente el tema de lo empresarial, reconociendo las dinámicas contextuales de la región en la cual estaban insertos estos actores sociales, apoyándose fuertemente en fuentes primarias para sustentar sus hipótesis, y ponderando los logros pero también las limitaciones de los mencionados empresarios.

Pese a la riqueza heurística e interpretativa subyacente en la propuesta de los autores mencionados, a mediados de los años 90s el Centro de Estudios Económicos Regionales, (CEER), liderado por los economistas Adolfo Meisel, Joaquín Viloria y la historiadora María Teresa Ripoll, comenzó a consolidar una nueva línea de interpretación que fue dejando de lado las mayores virtudes construidas inicialmente. De los contundentes análisis realizados en sus estudios de por qué se disipó el dinamismo industrial de Barranquilla, con hipótesis sustentadas en argumentos sólidos sobre el escaso eslabonamiento entre este puerto y su hinterland, y con ejercicios interpretativos de gran importancia sobre el impacto de las políticas centralistas en materia fiscal y de vías de comunicación en la Costa atlántica $^{12}$, Meisel comenzó a liderar unos estudios sobre empresas y empresarios en el Caribe colombiano que han ido reduciendo su campo interpretativo y el conjunto de variables que intervienen en la explicación de los temas que estudia.

\footnotetext{
${ }^{11}$ Sergio Paolo Solano y Jorge Conde Calderón, Elite empresarial y desarrollo industrial en Barranquilla, 1875-1930, Barranquilla, Universidad del Atlántico, 1993.

12 A. Meisel, “¿Por qué se disipo el dinamismo industrial de Barranquilla?”.
} 
A partir de una serie de estudios de casos, hagiografias de las principales familias que conformaban las elites económicas de ciudades como Barranquilla, Cartagena y Santa Marta, este grupo de investigación ha sustentado la hipótesis de que la Costa Caribe colombiana poseía una capacitada e innovadora elite empresarial, cosmopolita e integrada al mercado internacional, por lo cual no se debe argumentar que el atraso, estancamiento y rezago económico que experimentaron las principales ciudades de la Costa en el siglo XX derive o esté asociado a la ausencia de un grupo empresarial dinámico ${ }^{13}$. En ese esfuerzo, biografías sobre los Pombo, los Vélez Daníes, los del Castillo, los Martínez Camargo, los Mogollón o los Mier, se caracterizan por dotar a estos empresarios de un alto espíritu capitalista, con capacidad de riesgo, dedicados, laboriosos, honestos, y metódicos. Interesados en hacer de la descripción su elemento de construcción histórica más importante, detallan los lazos familiares, la vida de ocio y buen burgués que algunos desarrollaban, se resalta la diversificación a que se vieron "obligados" estos empresarios en los ámbitos del comercio, la agricultura, el transporte, la banca o la ganadería; se señalan los cargos políticos que ocuparon, y finalmente se destaca la relevancia que jugaron en el desarrollo de la región ${ }^{14}$.

Es esquema que se repite en casi todos sus estudios, poco problematiza el papel de los contextos y estructuras económicas, sociales y políticas en la cual están actuando toda esta serie de empresarios; la ausencia de una perspectiva comparativa con experiencias empresariales de otras regiones de Colombia u otros países, en términos de los capitales invertidos o de capacidad de riesgo, no les permite poner en su justa dimensión el papel de estos actores sociales; al contrario una visión teleológica termina seduciéndolos para reconstruir el exitoso trasegar de los mencionados empresarios. Preguntas centrales relacionadas con la vocación portuaria y comercial del Caribe colombiano no son tenidas en cuenta, o si se hacen lo usual es subvalorarlas o atenuar su impacto. Por ejemplo, la relación de estos empresarios con prácticas tan comunes en la región como el contrabando, el papel de los mismos en la escasa consolidación de un aparato productivo fuerte que jalonara de manera sostenida el desarrollo económico de la región o su responsabilidad en la construcción de proyectos políticos y sociales incluyentes en sus respectivas sociedades, son preguntas que merecen un mejor tratamiento o ser planteadas por este tipo de estudios para salir de la encrucijada en que se encuentran.

\footnotetext{
${ }^{13}$ María T. Ripoll, "La tradición mercantil en Cartagena en el siglo XIX", en H. Calvo y A. Meisel, Cartagena de Indias en el siglo XIX, y Adolfo Meisel, "Bajo el signo del cóndor: empresas y empresarios en el Caribe colombiano", Aguaita No 8, Cartagena, Observatorio del Caribe Colombiano, 2002.

${ }^{14}$ María T. Ripoll, "El Ingenio Central Colombia: inicios de la Industrialización en el Caribe colombiano", en Boletín Cultural y Bibliográfico, No 45, Bogotá, Biblioteca Luís Angel Arango, 1997; La actividad empresarial de Diego Martínez Camargo, 1890-1937, Cartagena, Cuadernos de Historia económica y empresarial del Caribe Colombiano, № 2, Banco de la República (CEER), 1999, Redes familiares y el comercio en cartagena: el caso de Rafael del Castillo \& Co, 1861-1960, Cartagena, Banco de la República, Cuadernos de Historia económica y empresarial, $N^{o}$ 5, 2000. Estos tres artículos, sumado a un análisis dedicado a los hermanos José Joaquín y Esteban Pombo, fueron recientemente reunidos por la autora en su texto Empresarios centenaristas en Cartagena. Cuatro casos de estudio. Y de Joaquín Vitoria, Empresarios de Santa Marta: El caso de Joaquín y Manuel Julián de Mier, 1800-1896, Cartagena, Banco de la República, Cuadernos de Historia económica y empresarial, № 7, 2000.
} 
Quizás uno de los últimos textos de la historiadora María T. Ripoll ${ }^{15}$ representa el mejor intento por sacar estos estudios del estancamiento en que se encuentran. Inicialmente presentado como un trabajo de grado para optar al titulo de maestría en historia, en la Universidad de los Andes, este texto tiene la virtud de romper con algunos de los esquemas anotados, pero al mismo tiempo denota ciertas continuidades que terminan socavando sus mayores logros. Aunque justificado bajo la misma pretensión de contribuir a explicar, a través del estudio de la elite dominante, la parálisis económica que experimentó Cartagena en el siglo XIX, este trabajo logra sacar el tema del ámbito estrictamente económico al que parecía estar condenado y lo ubica en un escenario de transición política como es de los inicios de la vida republicana, lo que le permite adentrarse en las relaciones de poder, en la reconfiguración de las elites, en el papel que jugaron los vínculos políticos y la misma guerra como variables de movilidad social o de posicionamiento y consolidación de algunos sectores empresariales. Igualmente es significativo su interés por establecer una perspectiva comparativa con las elites económicas de Cuba, Lima, Chile y Argentina, y con ello aventurar una posible explicación de por qué en Cartagena no hubo un desarrollo agrícola, ganadero o minero consolidado para salir de la parálisis mercantil que se generó después del proceso independentista, así como resalta su interés en visualizar las percepciones nada homogéneas de la elite frente a la ruptura con la corona española en 1810.

Este significativo esfuerzo por hacer uso de metodologías propias del discurso histórico se ve ensombrecido por su interés en distanciarse de interpretaciones historiográficas que no se corresponden con el cuadro que está intentado dibujar, y que la llevan a errores de correlación en las premisas para sustentar sus hipótesis. Este último punto se ve reflejado en la primera parte de su texto dedicada a la configuración socio-racial de Cartagena, donde dirige sus esfuerzos a describir las diferencias raciales y de clases existentes en los grupos sociales, específicamente en la gente común y corriente, y con ello llega a la conclusión de que en estos sectores la existencia de una conciencia de clase no era posible por la dificultad de establecer lazos de solidaridad por los niveles de estratificación, y porque "las gentes del común no constituían un grupo socio-racial homogéneo"16. Una cosa no lleva a la otra, y mucho menos es algo exclusivo de los sectores sociales cartageneros; es una condición presente en cualquier grupo social que poseen sus diferencias y jerarquías, pero eso no niega que en determinadas circunstancias históricas en defensa de sus necesidades puedan establecer lazos de solidaridad y de unidad ${ }^{17}$. Una herramienta metodológica que ha servido para "diseccionar" las expectativas de los distintos grupos sociales, termina siendo mal interpretada a partir de una definición del concepto de clase

\footnotetext{
${ }^{15}$ M. T. Ripoll, La elite en Cartagena y su tránsito a la República. Revolución política sin renovación social.

${ }^{16}$ M. T. Ripoll, La elite en Cartagena y su tránsito a la República, pp. 12, 18.

${ }^{17}$ Florencia Mallon, "The promise and dilemma of subaltern studies: perspectives from Latin American History”, in The American Historical Review vol. 99, № 5, diciembre de 1994, pp. 1491-1515.
} 
alejada de las tendencias contemporáneas que se han dedicado al análisis de los movimientos sociales ${ }^{18}$.

Pero mucho más significativo para el entendimiento de las continuidades que este texto posee es la relacionada con la visión que la autora construye en torno a la relación de los empresarios que estudia con el contrabando. La estrategia argumentativa comienza con la aceptación de que el comercio ilícito con extranjeros fue una práctica que estuvo a la orden del día a lo largo del periodo colonial en los territorios de ultramar, y que se intensificó con la interrupción del comercio trasatlántico, hasta el punto de convertirse en una "pandemia que abarcó toda la cuenca del Caribe y del Golfo de México..."19. Como consecuencia de lo anotado sugiere que la valoración sobre el contrabando debe ubicarse en el terreno de las percepciones, la idea debe ser "descifrar lo que en su fuero interno" los distintos sectores sociales pensaban sobre la mencionada práctica cuya permisividad absoluta era más que evidente. Centrada en el plano de las representaciones, en un contexto donde comprar, vender y especular eran los verbos que constantemente se conjugaban, Ripoll llega a una interpretación simplificadora al sugerir una suerte de inevitabilidad histórica del contrabando: la elite comercial contrabandeaba porque era algo "inevitable", algo " a lo que se habían visto obligados" 20 .

Tal cual como hace al abordar el tema de las tensiones socio-raciales, cuando se dedica infructuosamente a ubicar en las fiestas una serie de atenuantes de las jerarquías de raza y clase existentes en Cartagena, la idea deliberada es atenuar el peso del contrabando en el terreno de las prácticas sociales, sin referirse al hecho real y concreto que interesa en términos históricos para la historia empresarial: el contrabando, bien o mal visto, hizo parte del proceso de acumulación de capital de un buen número de empresarios tanto en el periodo colonial como en el republicano. Pero importa más justificación de ese comportamiento que el impacto que el mismo tuvo en la vida social, económica, cultural y política del Caribe colombiano, hasta el punto de simplificar realidades. Parte de los estudios que se han realizado sobre los empresarios extranjeros -en su mayoría por los integrantes de este mismo grupo de investigación- reproducen en gran medida los esquemas interpretativos hasta ahora descritos ${ }^{21}$.

18 Val Burris, "La síntesis neomarxista de Marx y Weber sobre las clases", en Julio Carabaña y A. de Francisco (comp), Teorías contemporáneas de las clases sociales, España, Pablo Iglesias, 1995, pp. $127-$ 156

19 M. T. Ripoll, La elite en Cartagena y su transito a la república, p. 57

${ }^{20}$ M. T. Ripoll, La elite en Cartagena y su transito a la república, p. 58. Un intento más amplio por atenuar el peso del contrabando en el proceso de acumulación de capital de los empresarios, a partir de la idea de practica generalizada, se encuentra en el articulo de esta autora "El comercio ilícito, un vicio de difícil curación cuando se contrae. (Una visión no moralista del contrabando intercolonial)", en Alberto Abello (comp.), El Caribe en la nación colombiana. Memorias, Bogotá, Museo Nacional de ColombiaObservatorio del Caribe colombiano, 2006, pp. 150-170.

${ }^{21}$ Este artículo fue escrito antes de que apareciera el libro de Muriel Laurent, Contrabando en Colombia en el siglo XIX. Prácticas y discursos de resistencia y reproducción, Bogotá, Universidad de los Andes, 2008, el que sin duda representa el estudio más detallado sobre el tema. 


\section{Los empresarios extranjeros y su segunda naturaleza}

Una esfera estrechamente vinculada a la historia empresarial es la de los estudios relacionados con el impacto de las corrientes inmigratorias que hicieron presencia en el Caribe colombiano. Alemanes, franceses, italianos, judíos sefardíes y, sobre todo, sirios, libaneses y palestinos fueron algunos de los inmigrantes que tuvieron una notable incidencia en la vida económica, política y social de la región, y sobre los cuales se han realizado diversas interpretaciones. Con excepción de algunas reflexiones de Jorge García Usta, quien estudió la influencia que los sirio-libaneses tuvieron en la gastronomía, la literatura y el arte, la gran mayoría de los estudios se han concentrado en analizar la inserción de los inmigrantes a las distintas sociedades del Caribe colombiano a partir de sus actividades económicas ${ }^{22}$.

Nuevamente Manuel Rodríguez y Jorge Restrepo, con su texto Empresarios extranjeros en Barranquilla, dieron origen a una serie de estudios sobre el papel que los inmigrantes tuvieron en la vida de las sociedades de la Costa Caribe. Por ser un trabajo inicial estos autores hicieron un análisis descriptivo y no analítico, que identificó los renglones productivos donde los mencionados inmigrantes tuvieron incidencia, cómo fue su proceso de acumulación de capital, y su posterior inclusión y articulación a la sociedad ${ }^{23}$. Trabajos posteriores han repetido este esquema hasta el punto de consolidar perspectivas que distan mucho de la problematización y complejidad que deben guiar el quehacer histórico. En esta línea se pueden ubicar los trabajos de Louise Fawcett, Eduardo Posada Carbó y Joaquín Viloria, quienes en distintos momentos y para variados espacios han realizado estudios dedicados a investigar la inmigración sirio-libanesa en la Costa Caribe ${ }^{24}$. Fawcett en su texto Sirios, libaneses y palestinos en Colombia publicado en el año de 1991, rastreó las causas del movimiento migratorio, las actividades económicas a las que se dedicaron, los ataques a los que se vieron enfrentados, y su final posicionamiento en los distintos ordenes de la sociedad. Esta investigación que pretendía tener una vocación nacional, pero que realmente encontraba sustento en la presencia de estos inmigrantes en Barranquilla, tuvo su mayor virtud en el tratamiento que la autora ofreció sobre las actividades económicas a las que se dedicaron sirios, libaneses y palestinos, al sugerir que no todos iniciaron su vida

22 Jorge García Usta, “Árabes en Macondo", en Deslinde № 21, Bogotá, Cedetrabajo, 1997; "La inmigración árabe, 100 años en busca de la segunda patria”, en El Universal, Cartagena, mayo 20 de 1984.

${ }^{23}$ Manuel Rodríguez y Jorge Restrepo, “Los empresarios extranjeros de Barranquilla, 1820-1900”, en G. Bell, El Caribe colombiano, pp. 139-193

${ }^{24}$ Louise Fawcett, Libaneses, sirios y palestinos en Colombia, Barranquilla, Universidad del Norte, Documentos Ceres, No 9, 1991; Louise Fawcett y Eduardo Posada, "En la tierra de las oportunidades: los sirio-libaneses en Colombia", en Boletín Cultural y Bibliográfico vol. 29, № 29, Bogotá, Biblioteca Luís Ángel Arango, 1992 y "Árabes y judíos en el desarrollo del Caribe colombiano 1850-1950", Boletín Cultural y Bibliográfico vol. 35, No 49, Bogotá, Biblioteca Luís Ángel Arango, 2000; Joaquín Viloria, Lorica, una colonia árabe a orillas del río Sinú, cuadernos de historia económica y empresarial, $\mathrm{N}^{\circ} 10$, Cartagena, Banco de la República (CEER), junio de 2003. 
como buhoneros, sino que era posible hallar sectores que se dedicaron a la agricultura, a la explotación del caucho o a reclamar posesión de tierras baldías ${ }^{25}$.

Pese a esta importante orientación metodológica, la autora, a la hora de establecer el exitoso proyecto económico de este grupo social, termina construyendo el esquema de estos inmigrantes como vendedores ambulantes, luego como propietarios de tiendas y su respectiva apertura de almacenes con sucursales, y finalmente el inversionista en los sectores de la industria, la agricultura, la ganadería y el transporte. A partir de este esquema, estrechamente asociado a las prácticas de austeridad y ahorro, Fawcett sustenta su argumentación de rápida capitalización de los mencionados inmigrantes, así como su consolidación y amplia participación en la vida económica y social de la región. Poco o nada señala el favorable contexto económico que se presentó en los años comprendidos entre 1880 y 1930, época en que se registra el punto más alto de esta inmigración, que concuerda con el despunte de la economía cafetera y la vinculación estable de Colombia al mercado mundial, y con ello se presenta una fuerte dinámica comercial importante que ayudó en parte a recuperar el puerto de Cartagena o a la consolidación del de Barranquilla $^{26}$.

Un año más tarde, la misma Fawcett, en compañía de Eduardo Posada, en su artículo En la tierra de las oportunidades: los sirio-libaneses en Colombia subsanó esta carencia metodológica al detenerse a estudiar las condiciones internas que facilitaron a los siriolibaneses sobresalir económica, política y socialmente en distinta espacios del país, entre ellos la Costa Caribe colombiana ${ }^{27}$. Con un estilo narrativo mejor logrado y con un buen tratamiento al tema de las políticas inmigratorias, estos autores resaltan el dinamismo económico en que se encontraba Colombia y la región Caribe en particular cuando llegaron los mencionados inmigrantes, quienes, ahora, pasan a jugar un "papel instrumental de enorme significado" en el contexto de desarrollo económico que marca ese periodo. Aunque es notorio el matiz que Posada con su visión de historiador le imprime al artículo, al subrayar el papel de los contextos, nuevamente se insiste en el esquema que exalta el paso del inmigrante de buhonero a empresario: "la maleta llena de mercancías...muy pronto le dio paso al almacén" 28 . Y por supuesto, esa especie de segunda naturaleza que constantemente los autores que hacen este tipo de análisis encuentran en estos empresarios saldría a la palestra: "en todas sus actividades...los sirio-libaneses demostraron poseer una extraordinaria devoción al trabajo, al que acompañaban su reconocida experiencia mercantil y...su mayor conocimiento de la evolución del comercio internacional" ${ }^{29}$.

25 L. Fawcett, Libaneses, sirios y palestinos, p. 19.

${ }^{26}$ Un análisis sobre la situación económica del contexto colombiano en ese momento la ofrece Jesús Antonio Bejarano, "El despegue cafetero (1900-1930)", en José Antonio Ocampo (comp.), Historia económica de Colombia, Bogotá, Biblioteca Familiar Presidencia de la República, 1997, y del mismo Ocampo Colombia y la economía mundial, 1830-1910, Bogotá, Universidad Nacional-Siglo XXIFedesarrollo, 1984.

27 E. Posada y L. Fawcett, "En la tierra de las oportunidades".

${ }^{28}$ E. Posada y L. Fawcett, "En la tierra de las oportunidades", p. 17.

${ }^{29}$ E. Posada y L. Fawcett, "En la tierra de las oportunidades", p. 20. 
Resulta sorprendente que en este segundo artículo, tan preocupado por analizar las circunstancias contextuales que favorecieron el posicionamiento de estos actores sociales, Posada, amplio conocedor de las dinámicas internas de la región, no haya hecho alusión al contrabando como una práctica central y característica de los circuitos comerciales donde tenían presencia tanto empresarios nacionales como extranjeros; ni siquiera se pregunta sí algunos inmigrantes incurrieron en este tipo de prácticas tan comunes desde el periodo colonial, como tampoco problematizan lo relacionado con los reclamos por posesión de terrenos baldíos, actividad inicial de algunos inmigrantes, sobre todo con la traumática e ineficaz política inmigratoria que marcó a Colombia, y que claramente ellos describen.

En el 2003, once años después de haberse publicado este artículo, Joaquín Viloria se interesó también por los inmigrantes sirio-libaneses, pero desplazó su mirada al municipio de Lorica, perteneciente a la rica provincia del Sinú, donde también se apostaron estos inmigrantes. Poca variación metodológica o innovación argumentativa supuso la interpretación ofrecida por Viloria en su texto Lorica, una Colonia árabe a orillas del Sinú $^{30}$. Este autor destaca los ataques sufridos por los inmigrantes a su llegada al país, describe las actividades a las que se dedicaron, resalta la importancia de Lorica a nivel comercial, y con ello establece la relación entre auge económico y presencia activa de los inmigrantes en la vida comercial de esta provincia. La hipótesis no ofrece ninguna variación, mas bien el matiz otorgado a partir de los contextos vuelve a perderse, y descansa totalmente en el espíritu laborioso y ahorrativo de este grupo social: "sus practicas austeras, su dedicación al trabajo, su espíritu emprendedor y su mentalidad mercantil, les facilitaron acceder a las oportunidades de negocios existentes en la región y en el país" ${ }^{\prime 3}$.

Esta misma interpretación lo lleva a analizar de forma errada los hallazgos que en torno al contrabando realiza en las fuentes primarias disponibles para Lorica. Preocupado porque su visión idílica de trabajadores austeros y honestos no se desdibuje, Viloria asume que el contrabando por el cual fueron reducidos a prisión los hermanos Chaguis, exitosos empresarios de nacionalidad siria, fue un caso aislado o excepcional; e incluso, a partir del sentido común y sin apoyarse en ninguna fuente documental, no solo establece que no se puede generalizar este tipo de actitudes sino que se trataban de situaciones que "no pasaron de malos entendidos con las autoridades locales" $" 32$. Y mucho más importante, llama la atención que a pesar de que su trabajo reposa fundamentalmente en los protocolos notariales, sobre los cuales tiene un articulo de cómo hacer uso de esta valiosa fuente ${ }^{33}$, no se haya fijado en el uso indebido de los terrenos baldíos (hipotecas, ventas), que cotejadas con la información que la prensa ofrece, le hubiesen permitido reconstruir el sin número de

\footnotetext{
${ }^{30} \mathrm{~J}$. Viloria, Lorica, una colonia árabe.

${ }^{31}$ J. Viloria, Lorica, una colonia árabe, pp. 34-35

32 J. Viloria, Lorica, una colonia árabe, p. 32

33 Joaquín Viloria. "el uso de las fuentes notariales con fines de investigación: el caso de la historia empresarial en el Caribe colombiano", en América Latina en la Historia Económica № 15, México, Asociación Mexicana de Historiadores Económicos, 2001.
} 
pleitos, denuncias y disputas en las que entraban los sirios y libaneses con particulares por este tipo de prácticas.

El texto de Sourdis ${ }^{34}$, al igual que el de Viloria y Meisel, luego de describir las actividades económicas a que se dedicaron y los renglones donde hicieron presencia (comercio, industria, transporte, ganadería, agricultura), no dudan en señalar que tanto alemanes y judíos sefardíes fueron quienes adelantaron los procesos de desarrollo más importantes en la mencionada ciudad. Según la interpretación de Meisel y Viloria "en la segunda mitad del siglo XIX el grupo empresarial que dominó la marcha de los negocios de Barranquilla fue el de los alemanes" 35 , y esa notable incidencia se vio reflejada en el progreso y modernización económica de la Barranquilla.

Sourdis, por su parte, apela a la acostumbrada caracterización de sus judíos sefardíes como "cultos, ahorrativos, innovadores, poseedores de una mentalidad capitalista" para hablar de su éxito en la economía barranquillera, y sin ponderar las transformaciones económicas que se están operando a nivel nacional e internacional en el contexto que está estudiando afirma que "al finalizar el siglo XIX, en buena parte gracias a su liderazgo (el de lo sefardíes) Barranquilla era ya el primer puerto colombiano..."36. Al poner en perspectiva comparativa los dos textos, por el interés de los autores en hiperbolizar el accionar de sus sujetos históricos, el lector termina preguntándose finalmente quienes adelantaron toda esa dinámica económica: ¿los alemanes, o los judíos sefardíes? Pero mas allá de eso - en el caso de Sourdis- nuevamente condiciones económicas y sociales de mayor peso en la definición de la supremacía portuaria de Barranquilla son pasadas por alto, trivializadas para ensalzar la importancia de su objeto de estudio, desconociendo los avances que ha producido la historiografía que ha abordado esa coyuntura histórica a partir de investigaciones sistemáticas y fundamentadas en amplias fuentes documentales.

Una de las consecuencias que pueden tener estos estudios es la creación de la imagen de un inmigrante que en condiciones de dificultades económicas logra un rápido éxito económico y se establece en los diferentes sectores de la estructura social, adjudicándole este éxito solo a una prácticas austeras y a su dedicación al trabajo como parte de la suerte de segunda naturaleza que supuestamente los caracteriza. Puede terminarse olvidando de ciertos inmigrantes en realidades inherentes a la región (el contrabando y el acaparamiento de tierras), al tiempo que puede desdibujarse el papel que habían jugado esos mismos empresarios nacionales y locales en la construcción de ciertos circuitos mercantiles y dinámicas comerciales que trascendían el ámbito de lo local y lo regional.

\footnotetext{
${ }^{34}$ Adelaida Sourdis, El registro oculto. Los sefardies del Caribe en la formación de la nación colombiana, 1813-1886, Bogotá, Academia Colombiana de Historia, 2001.

35 Joaquín Viloria y Adolfo Meisel, Los alemanes en el Caribe colombiano: el caso de Adolfo Held, 18801927, Cuadernos de Historia económica y empresarial No 1, Cartagena, Banco de la República (CEER), 1999, p. 8.

${ }^{36}$ A. Sourdis, El registro oculto, p. 111.
} 
La perspectiva que ha terminado dominando el acercamiento a las dinámicas económicas de los empresarios nacionales y de los inmigrantes en el Caribe colombiano, presentan ciertas problemáticas que es importante resaltar no para invalidar los estudios en mención, que si se superan - a nuestro modo de ver- pueden ayudar a salir de la encrucijada a unos estudios que en sus inicios ayudaron a mejorar el entendimiento de diversos procesos históricos, pero que ahora parecen estar condenados a no tener variación, y con ello se imposibilita el ejercicio de establecer nexos causales o puntos de encuentro con otras realidades y análisis históricos de esta compleja formación social.

\section{Desafíos de los estudios empresariales en la región Caribe}

Una de las falencias e insuficiencias subyacentes en los análisis que sobre historia empresarial hemos intentado subrayar, y que a la vez se convierte en su mayor reto y desafío, deriva de la dimensión más importante del oficio de historiar: intentar pensar históricamente. Narrar hechos, describir información sobre el pasado o aventurar hipótesis sustentadas con base en el sentido común no implica que se esté pensando históricamente; este ejercicio supone la necesidad de ubicar el objeto y los actores en estudio en un espacio y en un tiempo determinado, reconociendo las dinámicas de los contextos, identificando los "consensos", falencias y ritmos de la historiografía, así como también implica sustentar los argumentos a partir de las interpretaciones que las fuentes primarias ofrecen y no apoyarse simplemente en lo que el mencionado sentido común indica.

Puestas en el plano histórico e historiográfico muchas de las caracterizaciones que sobre los empresarios nacionales y extranjeros ha realizado el grupo de estudios empresariales, y quienes acríticamente han hecho eco de sus interpretaciones, pierden toda posibilidad de persuasión y convencimiento al no querer reconocer las especificidades propias del contexto que están analizando, y corresponderse mas bien con deliberadas posiciones de glorificar e idealizar sus actores sociales ${ }^{37}$. Un análisis comparativo del tratamiento que Posada, Viloria de la Hoz y Ripoll le han dado al tema del contrabando denota no una preocupación histórica sino una posición personal frente al tema. Ignorado por Posada en sus artículos sobre los sirio-libaneses y luego descrito como una fuerza impersonal -sin actores de carne y hueso- en las pocas líneas que le dedica en su obra El Caribe colombiano; descrito por Viloria como excepción tras el hallazgo de ciertos casos, y recientemente valorado como una realidad inevitable por Ripoll, el contrabando parece estar condenado a no ser contemplado como una realidad de fuerte impacto en la vida del Caribe colombiano y parte definitiva en el proceso de acumulación de capital de sus empresarios, aun cuando distintos estudios y fuentes así lo sustentan. Luís Fernando

\footnotetext{
${ }^{37}$ Un artículo que sigue de cerca estas interpretaciones es el estudio realizado por Claudia Navarro sobre José Vicente Mogollón, quien describe su exitoso paso de un "destartalado local" a una cadena de almacenes a lo largo y ancho del país; destacando variables como su laboriosidad y su espíritu altruista que lo llevo a preocuparse "por el bien general de la comunidad". Inicialmente presentado como trabajo de grado bajo el nombre "la actividad empresarial en Cartagena: el caso de José Vicente Mogollón 19001930, este texto con algunas variaciones, apareció publicado en la citada compilación de C. Dávila, Empresarios y empresas en Colombia con el nombre "J. V. Mogollón \& Cía. (1900-1930). Rayando Papel".
} 
González, sin lugar a dudas, quien mejor ha abordado el tema de los sirio-libaneses en Colombia, y a quien todos estos autores citan para hablar del accionar de estos inmigrantes en el circuito comercial conformado entre la provincia del Sinú, Cartagena y el Atrato, ha demostrado -siguiendo fuentes documentales- como las firmas A \& T Meluk y Abuchar hermanos se vieron involucrados en denuncias sobre mercancías de contrabando que recibían o enviaban hacia Panamá desde ese rico y complejo circuito comercial ${ }^{38}$.

Tanto los relatos de viajeros, la prensa y los documentos de hacienda y administración publica, que reposan en los fondo documentales del Archivo Histórico de Cartagena, reflejan de mil maneras como ciertos empresarios acostumbraban a hacer uso de este trafico ilícito. La caracterización que María T. Ripoll hace sobre Manuel Marcelino Núñez, tal vez el comerciante más poderoso de Cartagena en la primera mitad del siglo XIX, como "hombre hecho a si mismo", hubiese sido más completa, si en vez de idealizarlo, mostrara las multas que le fueron impuestas por evadir el pago de los derechos de importación de las mercancías que ingresaba al puerto de Cartagena y luego indultadas gracias a sus relaciones políticas ${ }^{39}$.

Iguales comentarios pueden hacerse de la forma como Viloria aborda los protocolos notariales, que como dijimos hasta estudio sobre el uso de los mismos tiene al respecto, donde no relaciona para nada el uso indebido de los terrenos baldíos y los conflictos y disputas -señaladas por la prensa- en torno a la apropiación de tierra por parte de los inmigrantes. A pesar que textos como los de Catherine Le Grand y Alejandro Reyes Posada han subrayado la complejidad de la estructura de la tenencia de la tierra en Colombia ${ }^{40}$, y otros como Orlando Fals Borda han mostrado como ciertos inmigrantes participaron en prácticas como el acaparamiento de tierra, Viloria no se interesó en esta variable o simplemente no la consideró como importante a la hora de estudiar el posicionamiento económico de los sirio-libaneses en Lorica. Tal vez influenciado por la hipótesis de Eduardo Posada de la existencia de un mercado libre de la tierra que facilitaba el libre acceso a la misma por parte de los colonos, no se detuvo a observar como los Abuchar o Checry Fayad hicieron uso indebido de los terrenos baldíos, o como ciertos inmigrantes acapararon miles de hectáreas de tierra, como el caso de Miguel Calume, quien, según Fals

\footnotetext{
${ }^{38}$ Luís Fernando González, "Sirio-libaneses en el Chocó. Cien años de presencia económica y cultural", en Boletín Cultural y Bibliográfico vol. 34, № 44, Bogotá, Biblioteca Luís Ángel Arango, 1997, pp. 73101.

${ }^{39}$ Archivo Histórico de Cartagena, Sección Hacienda, Cartagena, noviembre 15 de 1842 . La evasión del pago de derechos de importación era una practica constante, véase "Diligencias en causa de contrabando", "Nota del Sr. Procurador general del Estado acompañando una causa de contrabando", "Tribunal Superior de Justicia del Estado" en Gaceta Oficial del Estado Soberano de Bolívar, Cartagena, octubre 18 de 1863; octubre 18 de 1864 y junio 29 de 1865 respectivamente.

${ }^{40}$ Catherine Legrand, Colonización y protesta campesina en Colombia (1850-1950), Bogotá, Universidad Nacional, 1998; Orlando Fals Borda, Historia doble de la Costa, tomo IV el retorno a la tierra, Bogotá, Banco de la República-El Ancora eds., 2000; Alejandro Reyes Posada, Latifundio y poder político. La hacienda ganadera en Sucre, Bogotá, Cinep, 1978.
} 
Borda, en torno a las tierras de ciénagas, llego a acaparar cerca de 1.200 hectáreas que fueron destinadas para actividades como la agricultura y la ganadería ${ }^{41}$.

La preocupación por hacer de los inmigrantes unos empresarios exitosos luego de afrontar las mil y una dificultades, los lleva a una falencia historiográfica fundamental: la escasa problematización de las relaciones existentes entre los empresarios nacionales y los mismos inmigrantes. Las preguntas no deben estar orientadas solo a describir que tipo de negocios y con quienes establecieron relaciones los empresarios nacionales, tal cual como lo hace María Teresa Ripoll, al referirse a las conexiones existentes entre la casa Rafael del Castillo y algunos inmigrantes ${ }^{42}$, sino que también deben intentar subrayar de que forma empresarios locales y nacionales, con las dinámicas comerciales creadas, ciertos renglones de producción definidos y circuitos comerciales creados allende lo local y lo nacional, facilitaron el proceso de inserción de los inmigrantes. Sin embargo, el interés de magnificar el impacto de este grupo social en el desarrollo económico de la región los lleva a perder de vista esta variable, e incluso hasta sus propios hallazgos en relación con las dinámicas comerciales existentes antes de la llegada de los mencionados inmigrantes son dejados de lado.

Quizás donde se hace evidente esta última apreciación es en el texto de Joaquín Viloria sobre los sirio-libaneses en Lorica. Antes de la publicación de este trabajo, Viloria en el ensayo "Cereté, municipio agrícola", destaca el amplio movimiento comercial que caracterizaba este municipio y en general a la provincia del Sinú, y con ello resalta el papel de empresarios como los Brango, los Puche, los Burgos, entre otros ${ }^{43}$, quienes desde la segunda mitad del siglo XIX -hasta donde sabemos- no solo tenían contactos comerciales con Cartagena, sino con países como Panamá, Cuba, Estados Unidos, y con algunos puertos europeos. Paradójicamente en su texto "Lorica, una colonia árabe a orillas del río Sinú", termina suscribiendo las apreciaciones del periodista Antolin Díaz o las del viajero B. Le Roy Gordon, que se sintetizan en una incipiente vida comercial que solo será dinamizada con la llegada de los inmigrantes sirio-libaneses o empresarios de otras zonas. A estos seres, "llegados al azar, sin conocer el idioma, afrontando las dificultades del trópico...y costumbres diferentes" ${ }^{44}$, como los caracteriza Viloria, se les adjudica el desarrollo y dinamismo de las zonas donde se asentaron.

Ese afán por hiperbolizar el accionar de los empresarios, aparte de inducirlos a dejar de lado los avances que en el tema ha realizado la historiografia (incluido sus propios

41 Ana Milena Rhenals, Los inmigrantes sirio-libaneses en el Caribe colombiano, y O. Fals, Historia doble de la Costa, pp.157-158-A. Una investigación que insiste en la recurrencia de este tipo de prácticas en la zona del Sinú pueden verse en Alberto Alzate y Berta Brunal, Tenencia y concentración de la tierra en Córdoba, Montería, Fundación del Caribe, 1982, p. 23. Una visión crítica al argumento de Posada sobre la existencia de un mercado libre de tierras puede verse en S. Solano y R. Flórez, "Resguardos indígenas, ganadería y conflictos sociales en el Bolívar Grande, 1850-1875”, pp. 92-117.

42 M. T. Ripoll, "Redes familiares y el comercio en Cartagena", p. 21

${ }^{43}$ Joaquín Viloria, Cereté, municipio agrícola del Sinú, Documento de trabajo sobre economía regional, No 26, Cartagena, Banco de la República (CEER), 2002.

${ }^{44}$ J. Viloria, Lorica, Una colonia árabe a orillas del Sinú, pp. 35, 50. 
hallazgos), o no reconocer los aspectos contextuales de las realidades que analizan, termina por restarle contundencia a los escasos ejercicios comparativos que intentan establecer. La buena perspectiva comparativa que Ripoll introduce en su texto sobre el tránsito de la elite a la república para explicar la no existencia de una estructura agraria o minera en Cartagena, deja clara la responsabilidad e incidencia de esta elite y en general la de la Costa Caribe en la escasa consolidación de un aparato productivo fuerte. Pero, claro, no se fija en un elemento que su mismo análisis está mostrando y que ha sido señalado por la historiografía que ha estudiado la mentalidad empresarial que caracterizó a este conglomerado social en esta región: la mayoría de estos actores sociales terminaron apegados a las funciones de intermediarios del comercio, pequeños exportadores de ganado y transportadores, y más bien fueron proclives a una inusitada diversificación de inversiones, siendo restringida la posibilidad de acumular grandes fortunas en el contexto nacional y mucho menos en el internacional. En su excelente estudio sobre las limitaciones del desarrollo industrial de Barranquilla, aparte de plantear estas ideas, el historiador Sergio Paolo Solano demuestra que la mayoría de los empresarios de este puerto que invirtieron en la industria a comienzos del siglo XX habían perdido sus contactos con el comercio internacional a gran escala y se movieron hacia una serie de actividades con márgenes de ganancias menores, hasta el punto que solo el empresario antioqueño Vicente B. Villa superaba la fortuna que a lo largo de su vida acumularon ocho de los empresarios más representativos de Barranquilla ${ }^{45}$.

Pero Ripoll, en vez de esta importante contextualización que de forma implícita se puede colegir de sus análisis comparativos para hablar de cómo esta mentalidad empresarial también fue uno de los elementos que incidió - en parte- en la mera figura de los puertos del Caribe como centros de tránsito y acopio, prefiere recurrir a dos viejas figuras utilizadas por los autores que lideran el proceso de idealización de las elites: la primera fue retomar aquella conocida hipótesis esbozada en los años 60s del siglo XX por Rodolfo Segovia, y recientemente suscrita por Haroldo Calvo, que achaca la causa primordial de la decadencia económica de Cartagena durante el siglo XIX a la pérdida de lo mejor de su elite ilustrada en el proceso de la independencia ${ }^{46}$. Y la segunda, con un mayor grado de simplificación en términos de argumentación, es acudir a ese suerte de inevitabilidad histórica que parece marcar las actitudes de los empresarios: así como se vieron obligados a contrabandear, así mismo fueron sectores "propensos a la diversificación en sus

45 Sergio Paolo Solano, "Acumulación de capital e industrias. Limitaciones en el desarrollo fabril de Barranquilla, 1900-1934", en Historia y Cultura No 2, Cartagena, Universidad de Cartagena, 1993, pp. 193-228.

${ }^{46}$ Rodolfo Segovia, "Teoría de Cartagena. Por qué se pierde un siglo?", en Donaldo Bossa, Cartagena Independiente. Tradición y desarrollo, Bogotá, Tercer Mundo, 1967; Haroldo Calvo, "A la sombra de La Popa: el declive de Cartagena en el siglo XIX", en Adolfo Meisel y Haroldo Calvo (eds.), Cartagena de Indias en el siglo XIX, Bogotá, Banco de la República-Universidad Jorge Tadeo Lozano, 2002; M. T. Ripoll, La elite en Cartagena y su transito a la república, p. 103. El historiador Germán Colmenares, criticando esta posición, había advertido que los rigores de la independencia más que ser calculados en términos de perdidas de vida debían medirse en función del impacto que tuvo en la reconfiguración de los circuitos mercantiles y en general las relaciones de poder. Germán Colmenares, "El tránsito a sociedades campesinas de dos sociedades esclavistas en la Nueva Granada: Cartagena y Popayán, 1780-1850", en Huellas No 29, Barranquilla, Uninorte, 1990. 
inversiones, no como una opción sino obligados por la inestabilidad económica e institucional del país en el siglo pasado" ${ }^{47}$.

Una mirada atenta a otras historiografías que durante mucho tiempo hicieron uso de este tipo de interpretaciones muestra cuales son los inconvenientes que posee la estructura argumentativa apologética de los estudios empresariales en la región caribe colombiana. Diversos analistas que habían estudiado el caso antioqueño durante mucho tiempo acudieron a este tipo de explicaciones superficiales para explicar el desarrollo industrial de Antioquia. El espíritu empresarial, emprendedor y pujante, así como la ascendencia y orígenes judíos y vascos de los habitantes de este departamento, fueron algunos de las visiones idílicas que -al igual a las utilizadas en nuestro contexto- explicaban el inusitado movimiento económico que ubicó en los primeros lugares de la jerarquía industrial a la ciudad de Medellín. Cada vez las explicaciones iniciales de James Parsons, por ejemplo, sobre el carácter igualitario y democrático que revistió la ya famosa colonización antioqueña, fueron dando paso a interpretaciones que demostraron y siguen demostrando que lo que estuvo presente en el proceso de expansión de la frontera agrícola en ese departamento -liderado por los empresarios y terratenientes- fue un patrón de alta conflictividad y violencia en la apropiación y expropiación de tierras, así como una marcada explotación de los campesinos con una alta plusvalía como su correlato ${ }^{48}$.

Pese a que desde los años setenta la leyenda rosa de la segunda naturaleza de los empresarios antioqueños estaban siendo desmontadas, Posada en los años 90s y Viloria en el 2003 aún seguían haciendo uso de la mentalidad emprendedora y pujante de los antioqueños para explicar que los sirio-libaneses no encontraron condiciones favorables en este territorio para asentarse y hacer competencia ${ }^{49}$. Esta posición en parte encuentra explicación en la intención de estos autores por fortalecer la imagen de sus inmigrantes sirio-libaneses como seres dinamizadores de la economía de la Costa caribe, donde, a diferencia de Antioquia, encontraron ante todo un contexto comercial económico bastante precario y por desarrollar.

\footnotetext{
${ }^{47}$ M. T. Ripoll, Redes familiares, p. 1. Otro de los integrantes de este grupo que no tiene en cuenta la mentalidad empresarial que caracterizó a la elite económica del Caribe colombiano para explicar el posterior proceso de rezago económico que enfrentó la región es Adolfo Meisel. Este autor, intentando encontrar las claves para explicar este proceso, subraya como principal causa el fracaso del sector exportador, pero solo hace alusión a variables macroeconómicas que intervienen en el mismo, y al cambio en las correlaciones de las fuerzas políticas que derivaron hacia un marcado centralismo. Aunque ambas premisas son contundentes, hubiese sido interesante que el autor explorara como esa mentalidad diversificadora intervino en el hecho de que estos puertos fueron solo centros de acopio o redistribución. Adolfo Meisel, ¿Por qué perdió la Costa Caribe el siglo XX? Documentos de trabajo sobre economía regional, No 7, Cartagena, Banco de la República, (CEER), enero de 1999

48 James Parsons, La colonización antioqueña del occidente colombiano, Bogotá, 1961. Artículos que plantean una visión critica a la obra de Parsons puede verse en Marco Palacios, "Colonizaciones y exportaciones en la segunda mitad del siglo XIX", y "El espejo de los enigmas: la arquitectura de la colonización antioqueña", en La clase más ruidosa y otros ensayos sobre política e historia, Bogotá, Norma, 2002, pp. 58-94.

${ }^{49}$ E. Posada, “Árabes y judíos en el desarrollo del Caribe colombiano”, J. Viloria, Lorica una colonia árabe, p. 90
} 
Pero lo que nos interesa subrayar con relación al caso antioqueño son la implicaciones historiográficas que el abandono de las hipótesis superficiales supuso. Al dejar de lado las imágenes idílicas, fueron encontrando las especificidades que realmente marcaron las dinámicas del desarrollo empresarial e industrial de esa región. La conexión de sus empresarios con la estructura de poder, su definitoria participación política en el triangulo de oro formado por Bogotá-Cali-Medellín, expresado en una políticas de corte centralizante que favorecieron el mencionado dinamismo de estas ciudades, aunado a los márgenes de rentabilidad y de acumulación de riquezas que dejó el proceso de expansión de la frontera agrícola, son algunas de las explicaciones estructurales que se han resaltado para entender en parte la supuesta singularidad que caracterizaba los procesos del mundo antioqueño ${ }^{50}$.

Una reflexión de gran importancia para oxigenar los estancados estudios empresariales de la Costa Caribe derivan de las variaciones historiográficas anotadas para la realidad antioqueña: la necesidad de sacar los estudios del ámbito estrictamente económico y correlacionarlos con los avances de la historia social y política. Una interpretación sensata sobre los empresarios en el Caribe colombiano debería reconocer que el contrabando jugó un papel central en el proceso de acumulación de capital de varios empresarios nacionales y extranjeros tanto en el periodo colonial como durante buena parte de la vida republicana; que los renglones de producción identificados y establecidos, así como los circuitos y dinámicas comerciales lideradas por los primeros facilitaron la inserción de diversos inmigrantes a la vida económica de la región, sin perder de vista -claro está- que en el punto más alto de la inmigración (1880-1930) la región gozaba de unas condiciones económicas favorables derivadas de la condición portuaria de sus principales ciudades y provincias $^{51}$.

Los estudios empresariales en el Caribe colombiano también necesitan abrirse con más contundencia a los ámbitos político y social, no cuestionándose solo por cuántos y qué tipo de cargos ocupó un individuo, sino preocupándose por las relaciones de poder que construyeron desde los mismos. El historiador Alfonso Fernández Villa, a través del concepto de redes sociales, logra hacer un buen ejercicio del estudio de la elite de esta región a partir de las variables de guerra civil y clientelismo; llamando la atención de la centralidad que le otorgaban mucho de los empresarios a la política al considerarla el camino directo para acceder a los recursos que solo el Estado podía otorgar: tierras públicas, exenciones fiscales, remate de rentas públicas o contratos eran activos igual o más importantes que la posesión de capital. Esta variable -según Fernández- jugó un papel central para unas elites económicas como las del caribe colombiano y la del país en general que, a diferencia de las elites de Lima, México o Río de Janeiro, no dispusieron de grandes

\footnotetext{
${ }^{50}$ Marco Palacios, Entre la legitimidad y la violencia, 1875-1994, Bogotá, Norma, 1995, y María Teresa Uribe y Jesús María Álvarez, Raíces del poder regional: el caso antioqueño, Medellín, Universidad de Antioquia, 1998, y Mary Roldán, A sangre y fuego. La violencia en Antioquia, Bogotá, Icanh-Fundación para la Promoción de la Ciencia y la Tecnología, 2002.

${ }^{51}$ Este marco interpretativo, aunado a otras variables, deriva del trabajo de A. Rhenals, Inmigrantes siriolibaneses en el Caribe colombiano.
} 
capitales, y que más bien hicieron un fuerte uso de una tradición clientelar de alto raigambre colonial ${ }^{52}$. En esta misma dirección, las investigaciones adelantadas por el historiador Roicer Flórez Bolívar, sobre la administración pública en los territorios del actual Caribe colombiano, han sustentado cómo a través del control de este ramo de importancia en el funcionamiento del Estado, las elites económicas, ante la inexistencia de un monopolio de la violencia, de un aparato burocrático fuerte y de un monopolio fiscal, terminaron justificando el uso privado de la autoridad pública con un gran impacto en la vida social y política del Estado Soberano de Bolívar durante buena parte de la segunda mitad del siglo XIX. Elecciones, cargos públicos, concesiones, remates de impuestos, disposición de armas e infracciones a las normas y leyes, y todo cuanto estuviera relacionado con el funcionamiento y el ejercicio del poder, estuvo mediatizado por la nociones de autoridad o más bien de autoritarismo que lograron establecer como visiones dominantes los terratenientes, comerciantes, ganaderos y políticos que integraban la elite política, económica y social del periodo señalado ${ }^{53}$.

La importancia de esta apertura hacia lo social y lo político radica, ante todo, en la posibilidad de establecer los nexos causales existentes entre las bases de poder económico descrito por los estudios empresariales y las configuraciones socio-políticas que resultaron de la interacción de las visones de los sectores empresariales y el resto de conglomerados sociales. Tal vez las realidades del presente con sociedades marcadas por la exclusión y las jerarquías en términos de clase y raza, aunada al temor de encontrar dinámicas sociales y políticas alejadas de la imagen idílica que han construido sobre los empresarios en el Caribe colombiano, no seduzca al Centro de Estudios Económicos Regionales a aventurarse a este tipo de análisis. Quizás esa noción de desarrollo de la región que se les adjudica a estos empresarios, pierda su sentido o adquiera otro matiz cuando trasciendan lo meramente económico y se analice la responsabilidad social y política de este grupo social en el tipo de sociedades que terminaron construyéndose en este territorio. Los marcos interpretativos de estos autores -por su vocación apologética- difícilmente podrán explicar, por ejemplo, las actitudes de los directivos de la casa comercial Rafael del Castillo a comienzos del siglo XX, cuando realizaron una serie de gestiones para evitar que mano de obra negra proveniente del Caribe insular no ingresara a los puertos del Caribe colombiano por considerarla biológicamente inferior y perjudicial para el "mejoramiento de la raza"

Pero la historia esta llena de estas complejidades, los tonos grises son mucho más comunes que las imágenes de una sociedad a blanco y negro; los esquemas entre buenos y malos

\footnotetext{
${ }^{52}$ Alfonso Fernández, "Clientelismo y guerra civil en Cartagena. Sobre las estrategias políticas de la elite cartagenera, 1885-1895”, en Memorias $\mathrm{N}^{\mathrm{2}}$ 2, revista digital de arqueología e historia, Barranquilla, Universidad del Norte, 2002. http://www.uninorte.edu.co/publicaciones/memorias/memorias 2/articulos/articuloalfonsofernandezcorregido.pdf (Consulta: febrero 23 de 2007). En esta revista ver el artículo de Greys Verbel.

${ }^{53}$ Roicer Alberto Flórez, El uso privado de la autoridad pública en el Estado Soberano de Bolívar, 18631878. Universidad Pedagógica de Tunja-Universidad de Cartagena, Cartagena, 2007, tesis para optar el titulo de magíster en Historia de Colombia.

54 Francisco Javier Flórez, Rastros, rostros y voces del racismo institucional en Cartagena: un acercamiento a partir del debate de la degeneración de las razas, 1910-1930. Cartagena, 2007. Inédito.
} 
difícilmente logran ser contundentes en el ejercicio de reconstrucción histórica. Superar estos marcos interpretativos que rayan en lo idílico, pensar históricamente, así como abrirse a la historia política y social con el propósito de establecer puntos de encuentros, a nuestro modo de ver, son parte de los retos y desafíos que enfrenta hoy la historia empresarial en el Caribe colombiano. De la mayor o menor aprehensión y puesta en practica de este tipo de ejercicios -creemos- depende la posibilidad de lograr variaciones historiográficas y argumentativas en los análisis realizados, o sencillamente seguiremos leyendo artículos y textos donde solo cambian los sujetos pero el predicado es el mismo. 